\title{
Indigenous fishing techniques and their effectiveness as perceived by fishers in Cachar District, Assam, India
}

\author{
KAPIL DEB NATH ${ }^{1}$, SIMANKU BORAH ${ }^{2}$, BARKHA RANI CHETIA ${ }^{3}$, NABADEEP SAIKIA ${ }^{1}$, \\ BHASKAR J. SAUD ${ }^{2}$ AND R. K. MAJUMDAR ${ }^{4}$ \\ ${ }^{1}$ Krishi Vigyan Kendra, Assam Agricultural University, Arunachal, Cachar - 788 025, Assam, India \\ ${ }^{2}$ Regional Centre of ICAR-Central Inland Fisheries Research Institute, HOUSEFED Complex, Dispur \\ Guwahati - 781 006, Assam, India \\ ${ }^{3} I C A R$-Central Institute of Fisheries Education, Versova, Andheri (W), Mumbai - 400 061, Maharashtra, India \\ ${ }^{4}$ College of Fisheries, Central Agricultural University, Lembucherra - 799 210, Tripura, India \\ e-mail:drrkmcof@gmail.com
}

\begin{abstract}
The present study investigated traditional fishing devices namely Bundh, Dori and Gori Jal operated by fishers of Cachar District, Assam in rivers and small canals. The study was carried out in Ghagra River and adjoining small canals. Water current as well as indigenous knowledge of fishers on movement of fishes and foraging behaviour of freshwater prawns were found to be utilised to a great extent to catch the target species. Assessment of the effectiveness and rationality as perceived by fishers and experts respectively showed that Bundh fishing was highly effective Mean Perceived Effectiveness Index (MPEI score >2.5) whereas the other two fishing techniques namely Dori and Gori Jal were effective (MPEI score >2). All the three indigenous fishing techniques were found to be rational with a mean score $\geq 3$.
\end{abstract}

Keywords: Bundh, Cachar, Dori, Ghagra River, Gori Jal, Traditional fishing technique

The present study was undertaken in the Cachar District of Assam in North-east India. Cachar District $\left(90^{\circ} 44^{\prime} \mathrm{E}\right.$ to $92^{\circ} 40^{\prime} \mathrm{E}$ long. and $24^{\circ} 22^{\prime} \mathrm{N}$ to $25^{\circ} 08^{\prime} \mathrm{N}$ lat.) is located in Barak Valley region of Assam with a total geographical area of $3786 \mathrm{~km}^{2}$. The district shares its boundary with Dima Hasao District in the north, the state of Mizoram in the south, Karimganj and Hailakandi districts of Assam and the states of Meghalaya in the east and Manipur in the west. The demographical profile of the district is constituted mostly by Bengalis along with a sizable population of Meitei Manipuris, Bishnupuriya Manipuris, Dimasas, Assamese and Rongmei-Nagas. The district has an undulating topography characterised by hills, hillocks, wide plains and low lying waterlogged areas locally called beels. The district of Cachar is endowed with rich aquatic resources comprising 3,359 ha under floodplain wetlands, 6,400 ha under ponds and tanks and 10,049 ha under derelict water bodies (Anon., 2014). The river Barak along with its tributaries namely Sonai, Jiri, Ghagra and Jatinga, from the riverine resources of this district.

Indigenous knowledge is that knowledge accumulated over generations of living in a particular environment and bears the distinction of being evolved in a particular community, generally passed by word-of-mouth through generations and not often recorded in writing. Limited documentations have been made pertaining to Indigenous Technical Knowledge (ITK) associated with fishing techniques in Barak valley, Assam (Purkayastha and Gupta, 2014). The Barak River and its tributaries flowing through the district along with numerous wetlands offer enough scope for fishing activities to the inhabitants. People living around these water bodies have acquired indigenous knowledge about the fish species occurring in the wetlands, their abundance, seasonality of occurrence, migration and behavioural patterns of different fish groups based on which specialised fishing techniques have evolved over the years. Fishers of Cachar District employ a variety of fishing techniques in the rivers, beels and small canals. The present study is an attempt to document and scientifically analyse indigenous fishing methods employed in Ghagra River and in small canals and assess their effectiveness as perceived by fishers of Cachar District, Assam, India.

The present study was carried out in river Ghagra (an important south bank tributary of River Barak) and 72 no. Changduar Kacha Nala (a canal) which is connected to River Ghagra, in Cachar District, Assam from August, 2015 to November, 2016 (Fig. 1). A total of 8 field surveys were conducted in four villages namely Kanchanpur, 


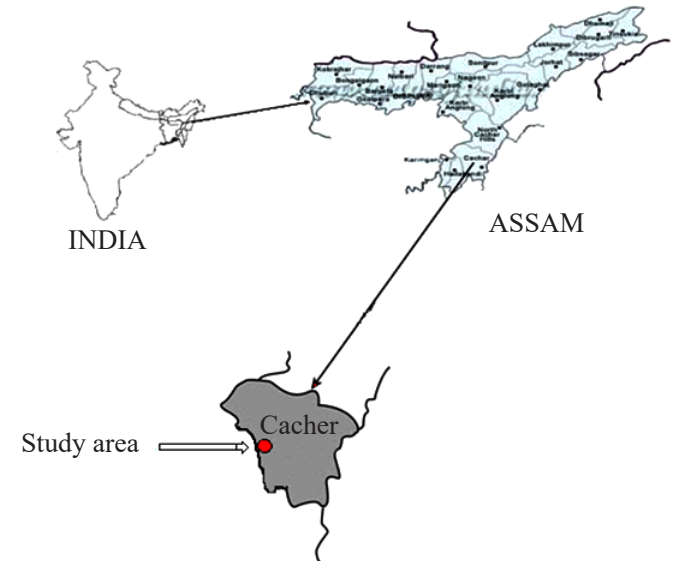

Fig. 1. Schematic diagram of the study area

Mangalpur, Natun Kanchanpur and Elginghat (24 $46^{\prime} 58^{\prime \prime}$ $\mathrm{N}$ lat. and $92^{\circ} 43^{\prime} 13^{\prime \prime} \mathrm{E}$ long.) situated along the bank of river Ghagra under Silchar Agricultural Circle of Cachar District, for observing the operation of different fishing techniques and their catch composition. The 72 no. Changduar Kacha Nala passes through the above mentioned four villages. The river Ghagra originates from Chatla Hower floodplain wetland and debouches into the Barak River near Chuktara Village after traversing an approximate distance of $40 \mathrm{~km}$. The people living in these four villages belong to the Bengali community and fall under scheduled caste (SC) category. The main occupation of the people in the surveyed villages was fishing and fish farming followed by agriculture. All the residents in the four villages were fish eaters. Participatory Rural Appraisal (PRA) methodology was adopted to collect information about indigenous fishing method amongst the villagers. Key informants included active fishers and elders of the villages. A total number of 30 active fishers and elderly villagers were consulted through one-to-one interaction for detailed documentation of the fishing method. Secondary information on these gears was obtained from fishers as well as other villagers using focused group discussions (Townsley, 1993; Schonut and Kieveltiz, 1994). Participatory observations were also made on the fishing operation in the river stretch. Prior Informed Consent (PIC) was obtained from community leaders/village heads of respective villages as per CBD guidelines in order to use and publish the recorded information on these indigenous fishing methods, because it was realised that the knowledge associated with these indigenous fishing methods need to be in public domain. The finfish and shellfish caught by the fishing devices were preserved in ice and brought to the laboratory for identification. Identification of fishes and prawns was done with the help of standard keys (Jayaram, 1999; Jayachandran, 2001).
Rationality of the three indigenous fishing techniques was judged according to Venkatesan and Sundaramari (2014). The documented practices and associated ITKs were send to a panel of experts $(n=20)$ in the field of Fisheries Science in the Regional Centre of ICAR-Central Inland Fisheries Research Institute (ICAR-CIFRI), Guwahati; Krishi Vigyan Kendras (KVKs) of Kamrup, Jorhat and Lakhimpur districts of Assam, College of Fisheries, Raha, Assam and Department of Fisheries, Assam and their response was rated on a 4 point scale. The fishing technique which was assigned a mean score of $\geq 3$ was considered rational and those with a mean score of $<3$ was considered irrational.

Perceived effectiveness of the fishing techniques and associated ITKs was measured using the Perceived Effectiveness Index (PEI) methodology given by Sundaramari (2001).

PEI $=\frac{\mathrm{W}_{1} \mathrm{R}_{1}+\mathrm{W}_{2} \mathrm{R}_{2}+\mathrm{W}_{3} \mathrm{R}_{3}+\mathrm{W}_{4} \mathrm{R}_{4}+\mathrm{W}_{5} \mathrm{R}_{5}+\mathrm{W}_{6} \mathrm{R}_{6}+\mathrm{W}_{7} \mathrm{R}_{7}+\mathrm{W}_{8} \mathrm{R}_{8}}{\mathrm{R}_{1}+\mathrm{R}_{2}+\mathrm{R}_{3}+\mathrm{R}_{4}+\mathrm{R}_{5}+\mathrm{R}_{6}+\mathrm{R}_{7}+\mathrm{R}_{8}}$

where, $\mathrm{W}_{1}, \mathrm{~W}_{2} \ldots \ldots \ldots \mathrm{W}_{8}$ are the scores obtained for the traits for an ITK for a respondent and $\mathrm{R}_{1}, \mathrm{R}_{2} \ldots \ldots \ldots \ldots \mathrm{R}_{8}$ are the relevancy weights of the eight traits.

To obtain the Mean Perceived Effectiveness Index (MPEI) for a particular ITK, the mean score of PEIs obtained from all the respondents $(n=30)$ for a particular ITK was calculated. MPEI score of 3 was regarded as the most effective; $>2.5$ as highly effective; $>2.0$ as effective; $<2.0$ as less effective and 1.0 was regarded as ineffective.

Fishers of Cachar District, Assam employ a variety of fishing gears such as cast net, lift net, gill net and hook and line, besides a variety of traditional fishing gears which has evolved over the years based on their knowledge and experience. The present study focussed on three different types of indigenous fishing devices operated by fishers of the district in rivers and canals.

\section{Indigenous fishing techniques}

Bundh: It is a community based traditional fishing method and operated in small canals during the months of May to October. This fishing technique is a combination of barrier fishing and nylon nets. The main body of the bundh is constructed with the help of 130-150 nos. of bamboos (Bambusa sp.) locally known as 'betua' and 'bakal'. During the process of construction, a series of bamboo poles having a diameter of $0.2-0.3 \mathrm{~m}$ and length of $8-10 \mathrm{~m}$ are inserted into the mud to a depth of around $1-1.5 \mathrm{~m}$ at regular intervals, covering the entire width of the canal with an opening of 0.5-0.7 $\mathrm{m}$ at the centre. Two ends of a small meshed nylon net of around 500-1000 m length 
(which may go upto $5000 \mathrm{~m}$ in monsoon) are knitted to the series of bamboo poles from both sides of the canal bank. The remaining part of the net is then passed through the opening at the centre of the barrier and installed along the river (Fig. 2). The length of the tail portion of the net is around $500 \mathrm{~m}$ and is a pouch like structure. The fishes moving along with the water current are collected in this tail portion. Expert fishers can construct a bundh within a period of 10-15 days and such a bundh has an operational life of around 1 year. Fishes moving along the flowing water are obstructed by the barrier and enter the tail portion of the net where they are trapped. The strong water current prevents escape of fishes. The catch from bundh mainly comprised Indian major carps, minor carps, cat fishes particularly Wallago attu, Sperata aor and Mystus sp., small indigenous fishes namely Puntius sp., Amblypharyngodon mola, Gudusia chapra and small freshwater prawns. The average catch per unit effort (CPUE) was estimated at 3-4 $\mathrm{kg} \mathrm{h}^{-1}$ and it was found to be a highly energy efficient fishing technique.

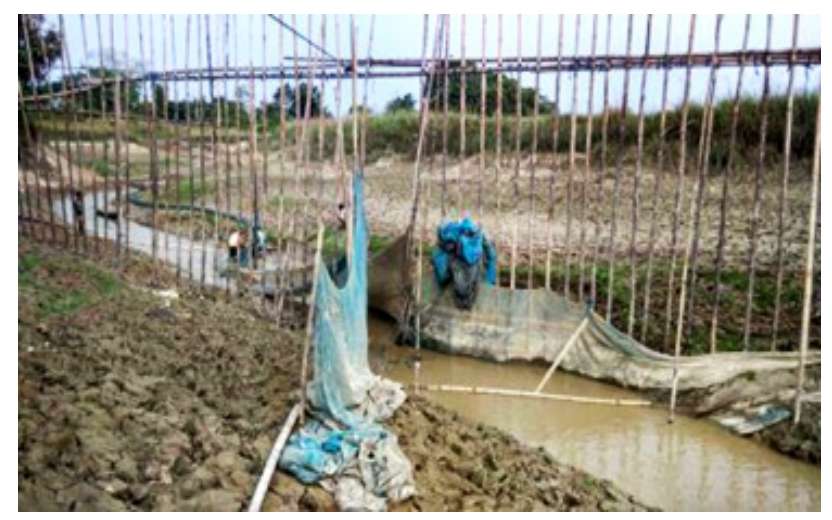

Fig. 2. Bundh fishing in a small canal

Dori: Dori is a traditional fishing trap operated in river Ghagra and adjoining small canals. It is a combination of barrier fishing and bamboo traps which is completely open towards the top (Fig. 3). The fishing trap is cylindrical in structure with a ' $\mathrm{V}$ ' shaped mouth supported by 4-5 bamboo strips fixed horizontally with the help of ropes.
The trap is made of slender, round bamboo strips with a length of $0.8-1.2 \mathrm{~m}$ and diameter of $1.5-2 \mathrm{~cm}$. It is operated in rivers during the months of September-March and in floodplain wetlands during April-August. It is installed in the marginal areas of rivers with slower water current and reduced water depth of around 0.4-0.6 m, with its mouth facing the current. Two pieces of small meshed nylon nets (3-3.5 $\mathrm{m}$ long and 1-1.5 wide) are fixed at the marginal areas of the river with the help of bamboo poles (1.5-2.5 $\mathrm{m}$ in length) in the form of a ' $\mathrm{V}$ ' shaped structure, maintaining a gap of $0.4-0.5 \mathrm{~m}$ towards the tapering end at which the bamboo trap is installed (Fig. 3). The trap is installed at the site of operation during evening and the catch is collected in the morning hours of the following day. The length and diameter of the traps vary from 0.8-1.2 and 0.3-0.45 $\mathrm{m}$ respectively. The net barriers obstruct the movement of fishes and are diverted towards the trap. Once the fishes enter the trap, the V-shaped mouth opening along with the force of the water current prevent its escape. Operational life of this fishing trap is around one year. The major catch in this fishing trap comprises small-sized species such as Mystus spp., followed by small indigenous fishes like A. mola, Puntius spp. and Chanda spp. At the time of harvest, the trap is brought to the bank and fishes are collected manually through the opening at the top. The average CPUE in this fishing gear was found to range from 2-2.3 $\mathrm{kg}$ over a time period of $12 \mathrm{~h}$. Dori is an energy efficient and cost-effective fishing technique.

Gori Jal: The fishing net locally known as Gori Jal is a specialised gear for catching freshwater prawn. Gori Jal is made of two different types of nylon netting material. The main body of the net is made of small-meshed netting (20 mm mesh size) with finer twine, and comparatively large-meshed netting (50-60 mm mesh size) with thicker twine and attached to a bamboo pole of $2.5-3.5 \mathrm{~m}$ in length and $0.15-0.2 \mathrm{~m}$ in dia. The main function of the large meshed netting is to prevent the floating debris from entering the main body at the time of operation. The debris encountered at the time of operation escapes through the wide meshes and ensures smooth operation of the fishing gear. The small-meshed nylon netting is locally known

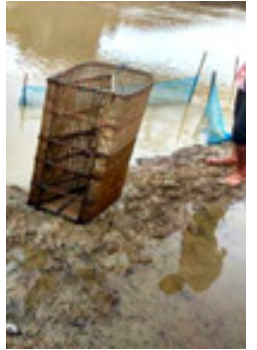

(a)

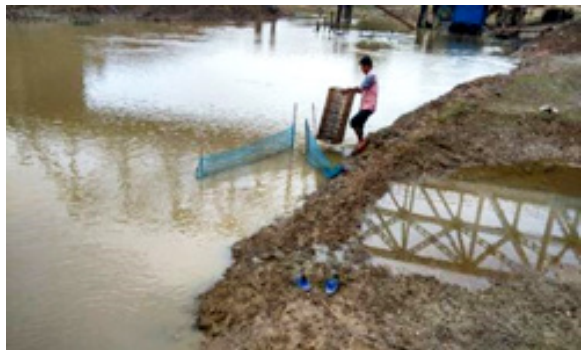

(b)

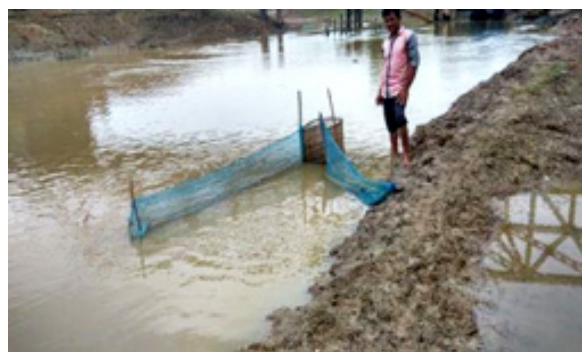

(c)

Fig. 3. Operation of Dori in Ghagra River 
among fishers as Bain Jal. The two ends of the smallmeshed netting material are stitched together to form a bag like structure (Fig. 4). The lower part of the mouth opening is attached with series of iron sinkers, weighing 2-3 kg which keeps the mouth vertically open at the time of operation. During operation, garbage is trapped to this net webbing and protects the main net webbing from damage. Operational life span of this fishing gear is about 2 years. The Gori Jal is operated during the months of September-January, when the water level in rivers recede. It is towed along the marginal areas of the river at a speed of $0.75-0.80 \mathrm{~m} \mathrm{sec}^{-1}$ with the help of a rope fixed to the bamboo pole and can be operated by a single person. In some cases the net is also towed from a boat (Fig. 5). The major catch is freshwater prawn, particularly Macrobrachium lamarrei along with small amount of bycatch in the form of small catfishes (e.g., Mystus spp.). Gori Jal is operated in the evening hours (after sunset) and in early morning (prior to sunrise). Freshwater prawns are nocturnal by nature and come out for foraging after sunset in the marginal areas of rivers with slow/mild water current. Fishers of Cachar District make use of this indigenous knowledge on the foraging behaviour of

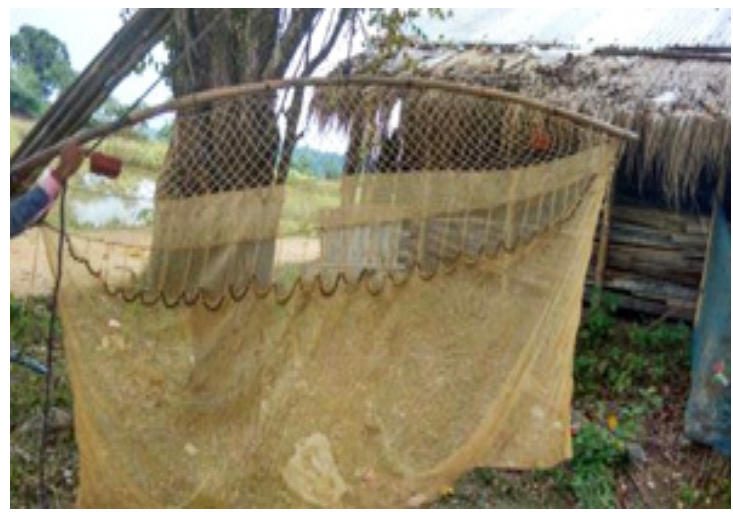

(a)

Fig. 4. Gori Jal

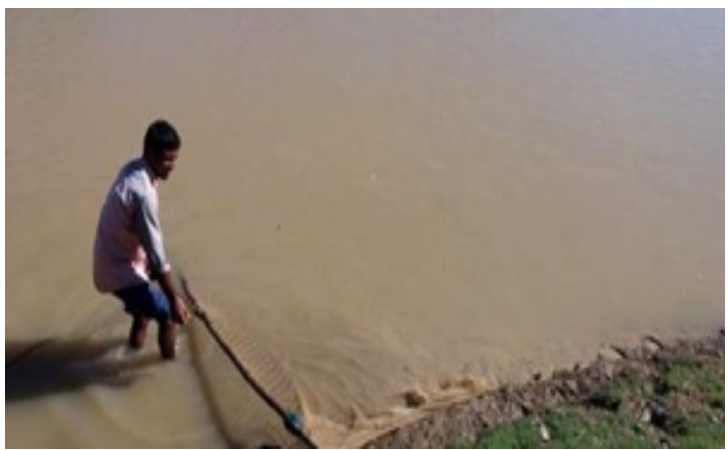

(a)

Fig. 5. Operation of Gori Jal in Ghagra River freshwater prawns to great extent. The CPUE in Gori Jal was found to range from $2-2.4 \mathrm{~kg} \mathrm{~h}^{-1}$.

Rationality and perceived effectiveness of the indigenous fishing techniques: Analysis of rationality revealed that all three indigenous fishing techniques were rational (mean score of $\geq 3$ ) according to the view of expert panel (Table 1). Assessment of effectiveness of the three indigenous fishing techniques as perceived by fishers of the district showed that Bundh fishing method is highly effective (MPEI score $>2.5$ ), while Dori and Gori Jal fishing techniques are effective with MPEI scores more than 2 (Table 1).

Several reports have been published pertaining to Indigenous Technical Knowledge (ITK) associated with fishing techniques in Brahmaputra Valley, Assam (Dutta and Bhattacharjya, 2009; Baruah et al., 2013; Barman et al., 2013); but reports on indigenous fishing techniques of Barak Valley, Assam is limited. Knowledge of fish behaviour (migration, feeding habits, habitat and seasonality of occurrence) which has been accumulated over generations, inhabiting a particular environment has been put into use by fishers in order to catch fish species. One of the most important skill of the fisherman is to use

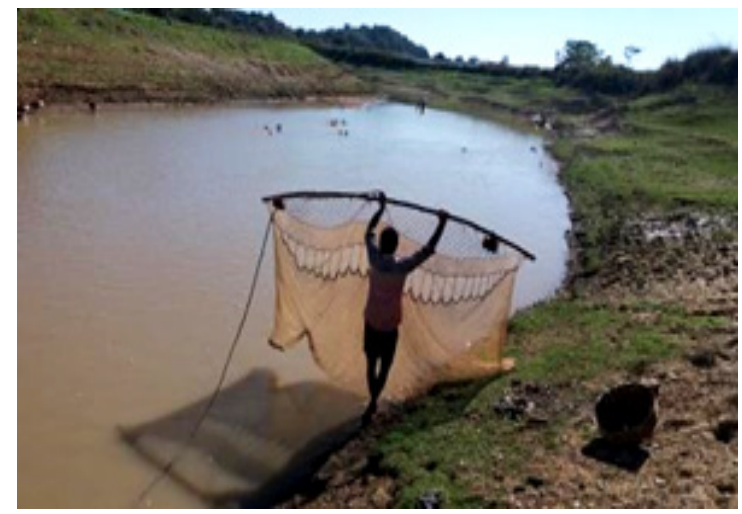

(b)

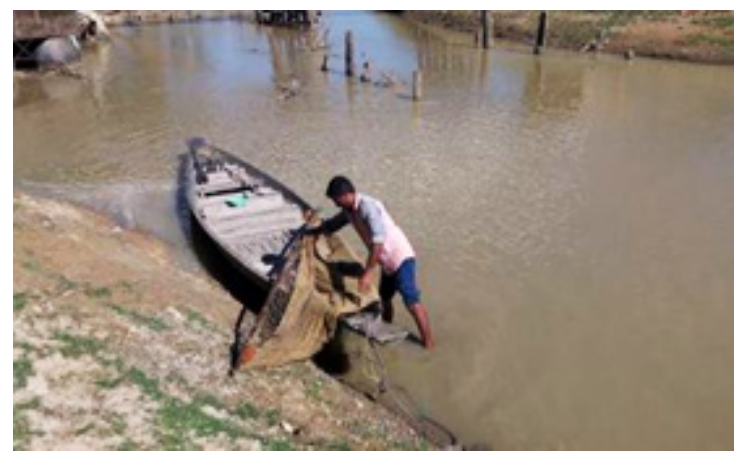

(b) 
Table 1. Rationality and effectiveness of indigenous fishing techniques in Cachar District, Assam, as perceived by experts and fishers

\begin{tabular}{llll}
\hline ITK & Rationality & MPEI & Remarks \\
\hline Bundh & Rational (3.57) & 2.62 & $\begin{array}{l}\text { Rational + Highly } \\
\text { effective }\end{array}$ \\
Dori & Rational (3.42) & 2.03 & Rational + Effective \\
Gori Jal & Rational (3.0) & 2.13 & Rational + Effective \\
\hline
\end{tabular}

the appropriate fishing technique at the right time in the right place (Wardle, 1986).

Smith and Brown (2002) stated that small sized fishes and macro-invertebrates are preyed upon by predatory fishes which are active in deeper waters as a result of which these small fishes and macro-invertebrates are dominant in shallow marginal waters. Dori is a fish trapping device employed in marginal areas of rivers along the path of fish movement to catch small sized fish species. Catching fishes by deploying traps along their path of movement is a common fishing method employed by traditional fishers all over the world (Von-Brandt, 1984). Traps are devices designed to encourage entry of animals, which are then prevented from escaping either by particular aspects of their behaviour or by design of the trap itself (King, 2007). In case of Dori, the 'V' shaped valves present at the mouth along with the force of water current prevents the escape of fishes by swimming backwards once they enter the trap. The same can be said with regard to Bundh method of catching fish. Once the fishes enter the net pouch, the force of water current prevents escape of fishes.

The target species of Gori Jal which is dragged along the river bed is Macrobrachium lamarrei. It is a bottom dwelling nocturnal macro-invertebrate species; which feed voraciously on planktonic organisms, algae, prawns and fish (Sharma and Subba, 2005); and found in marginal and swallower parts of water bodies. This particular nocturnal, bottom-dwelling behaviour and preference for shallow waters of the species has been utilised by fishers of Cachar District to catch the species with the help of Gori $\mathrm{Jal}$, which is operated by dragging it along the marginal areas of rivers just after sunset and prior to sunrise.

A number of studies have been reported on analysis of rationality and perceived effectiveness of ITKs in the field of agricultural science in India (Sundaramari, 2001; Husain and Sundaramari, 2011; Venkatesan and Sundaramari, 2014). However studies on rationality analysis and assessment of perceived effectiveness of ITKs in the field of fisheries science are limited (Devi et al., 2014; Saha et al., 2015). All the documented fishing methods in this study were found to be rational as judged by the expert panel. Based on our personal observation, it was seen that Bundh and Dori are energy efficient fishing gears. The CPUE was found to be quite high in case of Bundh and Gori Jal. Dori on the other hand is a cost effective fishing technique. Saha et al. (2015) studied the perceived effectiveness of indigenous traditional fishing methods including gears and traps according to fishers in Nogaon District of Assam. They found that the traditional fishing technique, Bheta di maas dhora which has some similarities with Bundh fishing is rational and highly effective, whereas traps such as Juti and Dingori, used along a bamboo barrier which has some similarities with Dori as documented in the present study, seems to be rational and effective. Purkayastha and Gupta (2014) documented Dori in their study on traditional fishing gears used by fishers of Chatla floodplain area of Barak Valley, Assam. They provided limited information on this fishing trap and reported that it is simple handmade, box type, automatic fish trap made of bamboo, costing around ₹ 150 - 300. This trap is installed in flowing waters and the valves present at the mouth prevent escape of fishes once they enter the trap. The present study on the other hand has attempted to provide detailed information with regard to the construction, mode and site of operation, principle of capture, catch composition and CPUE of the traditional fishing gears studied.

Indigenous technical knowledge accumulated by different fisher communities over the years has resulted in development of specialised fish harvesting methods/ gear. Assessment of applicability of the fishing methods as perceived by fishers and experts showed that these fishing methods are quite effective as well as rational. Such methods are crucial for ensuring livelihood and nutritional security of fishers. There is need to document such techniques along with associated ITKs so that the fishing gear/techniques can be upgraded for the benefit and economic empowerment of resource-poor fishers.

\section{Acknowledgements}

The co-operation of all the villagers, particularly fishers of Kanchanpur, Mangalpur, Natun Kanchanpur and Elginghat village are gratefully acknowledged. We also extend our sincere acknowledgement to key informers namely, Mr. Chandra Das (34 years), Mr. Ranu Das (32 years), Satish Das (52 years), Subudh Das (48 years) and Naresh Sarkar (45 years) of Mangalpur Village, Silchar Developmental Block, Cachar, Assam, who shared their valuable indigenous and traditional information about these fishing devices.

\section{Reference}

Anon. 2014. Statistical handbook of Assam. Government of Assam, 376 pp. 
Barman, J., Baruah, U. K. and Goswami, U. C. 2013. Indigenous techniques of catching the mud eel, Monopterus cuchia (Ham.) in Goalpara District, Assam. Indian J. Trad. Know., 12(1): 109-115.

Baruah, D., Dutta, A. and Pravin, P. 2013. Traditional fish trapping devices and methods in the Brahmaputra Valley of Assam, Indian J. Trad. Know., 12(1): 123-129.

Von-Brandt, A. 1984. Fish catching methods of the world, Fishery Newsbooks Ltd., Farnham Survey, England, $418 \mathrm{pp}$.

Devi, R., Saha, B., Pandit, A. and Kashyap, D. 2014. Assessment of applicability of Indigenous Technical Knowledge (ITK) in aquaculture as perceived by fish farmers in Assam. Indian J. Fish., 61(3): 104-110.

Dutta, R. and Bhattacharjya, B. K. 2009. A traditional fishing method of Assam for catfishes using duck meat as an attractant. Indian J. Trad. Know., 8(2): 234-236.

Husain, S. and Sundaramari, A. M. 2011. Scientific rationality and perceived effectiveness of indigenous technical knowledge on coconut (Cocos nucifera L.) cultivation in Kerala. J. Trop. Agri., 49(1-2): 78-87.

Jayachandran, K. V. 2001. Palaemonid prawns: Biodiversity, taxonomy, biology and management, Science Publishers Inc., Enfield (NH), USA, 624 pp.

Jayaram, K. C. 1999. The freshwater fishes of the Indian region, Narendra Publishing House, New Delhi, 551 pp.

King, M. G. 2007. Fisheries biology, assessment and management, Blackwell Publishing Ltd., Oxford, UK, $377 \mathrm{pp}$.
Purkayastha, P. and Gupta, S. 2014. Traditional fishing gears used by fisher folk of Chatla floodplain area, Barak Valley, Assam. Indian J. Trad. Know., 13(1): 181-186.

Saha, B., Devi, R., Kashyap, D. and Baruah, D. J. 2015. Perceived effectiveness of indigenous traditional fishing methods including gears and traps in Nogaon District of Assam. Indian J. Trad. Know., 1(1): 103-111.

Schonut, M. and Kieveltiz, V. 1994. Participatory learning approaches: Rapid rural appraisal; Participatory rural appraisal - An introductory guide, Springer-Verlag, Berlin, 183 pp.

Sharma, A. and Subba, B. R. 2005. General biology of freshwater prawn, Macrobrachium lamarrei (H. Milne-Edwards) of Birat nagar, Nepal. Our Nature, 3: 31-41.

Smith, K. F. and Brown, J. H. 2002. Patterns of diversity, depth range and body size among pelagic fishes along a gradient of depth. Global Ecol. Biodiv., 11: 313-322.

Sundaramari, M. 2001. Adoption and perceived effectiveness of indigenous agricultural practices in different farming systems. Ph. D. Thesis, Gandhigram Rural Institute, Gandhigram, India, 247 pp.

Townsley, P. 1993. Rapid appraisal methods for coastal communities, Bay of Bengal Programme, Chennai, Tamil Nadu, 110 pp.

Venkatesan, P. and Sundaramari, M. 2014. Scientific rationality, adoption and perceived effectiveness of traditional agricultural practices of cassava (Manihot esculenta Crantz.) in Kolli Hills, India. J. Root Crops, 40(2): 58-65.

Wardle, C. S. 1986. Fish behaviour and fishing gear, In: Pitcher, T. J. (Eds.), The behaviour of teleost fishes, Springer, US, p. 463-495. 